\title{
AVALIAÇÃO DA POTENCIALIDADE DA UTILIZAÇÃO DE UM ULTRAMICRODURÔMETRO PARA ANÁLISE DAS PROPRIEDADES MECÂNICAS DE UM AÇO DUAL PHASE*
}

Mônica Aline Magalhães Gurgel ${ }^{1}$ Andersan dos Santos Paula ${ }^{2}$

Fernando Generoso Neiva Ferreira ${ }^{3}$

\section{Resumo}

A crescente preocupação da indústria automobilística com questões ambientais e com a segurança do condutor e passageiros, fez com que o setor siderúrgico desenvolvesse aços com maior valor tecnológico, entre eles surgiu os aços avançados de alta resistência, onde encontra-se o "Dual Phase" (DP) utilizado nesse estudo, que é caracterizado por uma microestrutura associada a uma matriz ferrítica com ilhas dispersas de martensita. Neste trabalho utilizou-se amostras de um aço baixo $\mathrm{C}$ e $\mathrm{Mn}$, com micro adição de $\mathrm{Nb}$ e Mo, em desenvolvimento, onde se propôs uma avaliação das propriedades mecânicas através de um Ultramicrodurômetro, as amostras extraídas após a laminação a frio seguiram para o recozimento intercrítico, em escala laboratorial, com auxílio de forno Mufla e um equipamento de análise termomecânica (TMA), com 7 temperaturas de encharque distintas e subsequente resfriamento com patamar isotérmico a $600^{\circ} \mathrm{C}$ por 20 minutos. Onde observou-se que a utilização do ultramicrodurômetro instrumentado mostrou ser uma ferramenta com grande potencial para a avaliação almejada.

Palavras-chave: Aço bifásico; Recozimento intercrítico; Microestrutura; Ultramicrodurômetro instrumentado.

\section{EVALUATION OF THE POTENTIAL USE OF A ULTRAMICRODUROMETER FOR DP STEEL MECHANICAL PROPERTIES ANALYSIS}

\section{Abstract}

The growing concern of the automotive industry with environmental issues and the safety of the driver and passengers, made the steel industry to develop steel with higher technological value, including the advanced high strength steels has emerged, where is the Dual Phase (DP) used in this study, which is characterized by a microstructure associated with a ferritic matrix with dispersed martensite islands. In this work we used samples of a low-C steel with $\mathrm{Mn}$ and micro addition of $\mathrm{Nb}$ and $\mathrm{Mo}$, in development, where proposed an evaluation of mechanical properties through a Ultramicrodurômetro, the samples taken after cold rolling followed for annealing intercritical in laboratory scale with furnace and thermomechanical analyser equipament (TMA), with 7 different temperatures and subsequent cooling with isothermal plateau at $600^{\circ} \mathrm{C}$ for 20 minutes. Where it noted that the use of instrumented ultramicrodurômetro proved to be a tool with great potential for the evaluation desired. Keywords: Dual phase; Intercritical annealing; Microstructure; Instrumented ultramicrodurometer.

1 Eng. Metalurgista. M.Sc. pela PPGEM/UFF, Doutoranda em Ciências dos Materiais no PGCM/SE4- Instituto Militar de Engenharia, Rio de Janeiro/RJ, Brasil.

2 Engenheira Metalurgista, D.Sc., Professor Adjunta, Instituto Militar de Engenharia, Rio de Janeiro, RJ, Brasil; e orientadora credenciada da PPGEM/UFF, Volta Redonda, RJ, Brasil.

3 Eng.Metalurgista.M.Sc.Especialista de Desen. de Produtos da ArcelorMittal Tubarão, Vitória/ES,Brasil. 


\section{INTRODUÇÃO}

Preocupadas com questões ambientais, consumo de combustíveis e segurança, as indústrias automobilísticas fizeram com que a siderurgia investisse em desenvolvimento de materiais com maior valor tecnológico, ou seja, que atendessem as exigências desse ramo de indústria, surgindo assim materiais que proporcionam uma redução da sua espessura sem perda nas suas propriedades mecânicas. O que resultou nos últimos anos no surgimento de várias classes de materiais, capazes de substituir os aços ao carbono, como os aços de alta resistência ("High-Strength Steels" (HSS)), aços avançados de alta resistência ("Advanced High-Strength Steels" (AHSS)) e aços de ultra alta resistência ("Ultra High Strength Steels" (UHSS)), pois é na indústria automobilística que estão alguns dos desafios para a siderurgia, devido à complexidade e as propriedades exigidas. Dentre elas, tem-se o aço "Dual Phase" (DP), o qual pertence à classe AHSS, desenvolvido com principal objetivo de reduzir o peso dos veículos, sendo muito utilizado em peças que exigem elevada tenacidade. O aço bifásico ("Dual Phase" ou DP), alvo deste estudo, surgiu industrialmente ao final da década de 70, mas por ter limitações de processo e equipamentos siderúrgicos, teve dificuldades iniciais de ser difundido industrialmente, sendo mais estudado nas últimas décadas. Este aço possui uma microestrutura constituída de uma matriz ferrítica (macia) que está relacionada com a ductilidade e ilhas de martensita (dura) que contribui para a resistência mecânica, como essa microestrutura compreende uma mistura de fases, como mostrado na Figura 1, logo a denominação de aços bifásicos ("Dual Phase Steel"). Sendo assim, esses aços combinam uma considerável resistência mecânica, conformabilidade e boa soldabilidade, fatores importantes para suas aplicações.

Aço DP Ferrítico-Martensítico

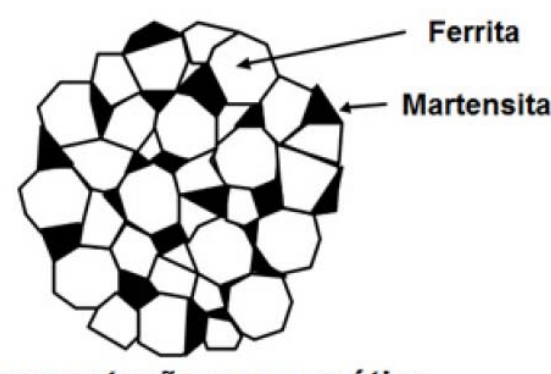

Representação esquemática
Ferrita (cinza) Martensita (branco)

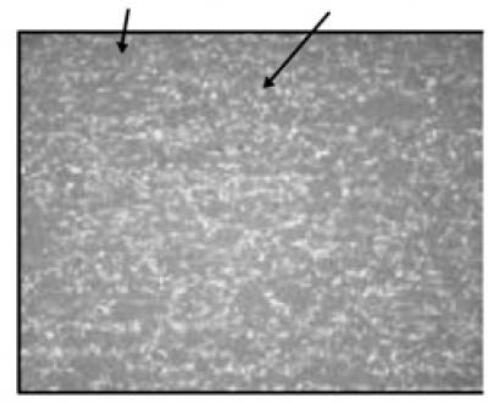

DP 340/600, 500x, Ataque: LePera

Microestrutura real

Figura 1. Representação esquemática e microestrutura real de um aço DP Ferrítico-Martensítico [1].

Como nos últimos anos ocorreu um aumento na utilização desses aços principalmente pela indústria automobilística brasileira para fabricação de carrocerias, fez-se necessário que as siderurgias também a âmbito nacional, aprimora-se seu conhecimento para desenvolvimento de aços bifásicos laminados a frio e recozidos. Para isso a siderurgia vem investindo em estudos, a fim de alcançar uma composição química específica e um melhor entendimento da evolução das suas características microestruturais, ao longo de todas as etapas de produção dos aços "Dual Phase", com uma maior ênfase na evolução da microestrutura durante o processo de recozimento, a fim de promover um desenvolvimento microestrutural adequado para obtenção das melhores propriedades exigidas nas aplicações desse material. 
Sendo assim este trabalho objetivou-se avaliar a potencialidade do uso de determinadas propriedades mecânicas extraídas a partir de medidas em um ultramicrodurômetro instrumentado, para além da dureza Vickers, de modo a obter uma massa crítica de dados durante as etapas de estudo acadêmico e desenvolvimento de produtos industrialmente com um volume reduzido de material. As amostras oriundas da laminação a frio foram submetidas ao recozimento intercrítico em escala laboratorial, sob distintas condições de ciclo térmico (taxas de aquecimento e resfriamento com patamar isotérmico a $600^{\circ} \mathrm{C}$ por 20 minutos), com auxílio de medidas extraídas de um ensaio de ultramicrodureza instrumentado e análise microestrutural via MEV para elucidação das condições microestruturais relacionadas, observando assim a influência desse ciclo para produção de chapas de aço "Dual Phase" laminadas a frio e recozidas. A fim de correlacionar com a evolução microestrutural do aço em estudo, em escala laboratorial (recozimento), em confronto com os resultados de propriedades mecânicas obtidas via ensaio de tração uniaxial (Limite de Escoamento, Limite de Resistência e Alongamento) do trabalho de Ferreira (2013), onde o material em estudo foi submetido ao recozimento intercrítico em 3 temperaturas de encharque distintas $\left(750,800\right.$ e $\left.850^{\circ} \mathrm{C}\right)$ e posterior resfriamento direto em 3 meios diferentes (água, ar e ar forçado).

\section{MATERIAL E MÉTODOS}

\subsection{Material}

O material avaliado nesse trabalho é um aço baixo carbono com adição de manganês e micro adição de Nióbio e Molibdênio. As amostras, doadas para este trabalho, foram retiradas ao longo do processo de produção industrial, ou seja, após o processo de laminação a quente (LQ) e laminação a frio (LF). Por questões de sigilo industrial, a faixa de composição química do material está representada pelas porcentagens dos elementos de liga na Tabela 1.

Tabela 1. Especificação da composição química do material em estudo

\begin{tabular}{cccccccc}
\multicolumn{7}{c}{ Composição Química (\% em peso) } \\
$\mathbf{C}$ & $\mathbf{M n}$ & $\mathbf{M o}$ & $\mathbf{N i}$ & $\mathbf{C r}$ & $\mathbf{A L}$ & $\mathbf{N b}$ & $\mathbf{S i}$ \\
$0,11-$ & $1,60-$ & $0,10-$ & 0,10 & 0,10 & 0,010 & 0,030 & 0,05 \\
0,15 & 1,80 & 0,30 & máx & máx & mín & máx & máx
\end{tabular}

\subsection{Métodos}

\subsubsection{Recozimento Intercrítico}

Amostras retiradas após a laminação a frio em escala industrial seguiram para um recozimento intercrítico em escala laboratorial, com auxílio de um TMA (Análise termomecânica), sem aplicação de carga, e um forno tipo Mufla, onde adotou-se temperaturas de encharque de $680,720,760,800,840,880$ e $920^{\circ} \mathrm{C}$ com permanência por 180 segundos (3 minutos) na temperatura máxima, sendo posteriormente resfriadas até a temperatura de $600^{\circ} \mathrm{C}$, nesse patamar isotérmico a $600^{\circ} \mathrm{C}$ (um pouco abaixo da temperatura $\mathrm{Ar}_{3}$ para condição de encharque a $680^{\circ} \mathrm{C}$ ) a amostra permaneceu por 20 minutos, seguido de um resfriamento até temperatura ambiente. Esse ciclo tem o intuito de buscar uma maior formação de ferrita epitaxial e enriquecimento da austenita durante o resfriamento favorecendo assim a maior formação de martensita. 
No TMA a taxa de aquecimento foi de $99^{\circ} \mathrm{C} / \mathrm{min}$ até distintas temperaturas de encharque, após o patamar na temperatura de encharque a taxa de resfriamento foi de $10^{\circ} \mathrm{C} / \mathrm{min}$ até o patamar de $600^{\circ} \mathrm{C}$, com permanência de 20 min e posterior resfriamento com taxa de $5^{\circ} \mathrm{C} / \mathrm{min}$ até a temperatura de $80^{\circ} \mathrm{C}$.

Para o forno Mufla, adotou-se um ciclo semelhante, onde novas amostras da condição $\mathrm{BFH}$ foram inseridas no forno pré-aquecido nas temperaturas de encharque adotadas no presente trabalho $\left(680,720,760,800,840,880\right.$ e $\left.920^{\circ} \mathrm{C}\right)$, onde de maneira análoga o tempo para início da manutenção na temperatura de encharque de 180 segundos, foi estabelecido com a indicação de uma temperatura de $-10^{\circ} \mathrm{C} /+0^{\circ} \mathrm{C}$ da temperatura de encharque almejada - a partir da medida do termopar fixado na superfície da amostra em tratamento. Ao término dos 3 minutos de encharque a amostra foi transferida para um segundo forno tipo Mufla (próximo do primeiro forno) pré-aquecido a $600^{\circ} \mathrm{C}$, onde o tempo para transferência foi cronometrado para todos os tratamentos e não ultrapassou 10 segundos. Ao fechar a porta do forno (segundo forno) foi contabilizado o tempo 20 minutos para permanência no interior do forno a fim de estabelecer o patamar isotérmico a $600^{\circ} \mathrm{C}$. Com o término do patamar isotérmico, a amostra foi extraída do forno e resfriada ao ar até ser estabelecida a temperatura ambiente. De modo a reduzir a perda térmica durante a transferência entre fornos Mufla, cada amostra foi inserida numa cavidade de um tijolo refratário pré-aquecido e homogeneizado na temperatura encharque de tratamento recozimento intercrítico em questão. Para o forno o perfil do ciclo térmico foi feito com base na coleta de um termopar acoplado a um sistema digital de aquisição de dados durante o tratamento térmico de recozimento.

As amostras que foram submetidas aos ciclos térmicos descritos anteriormente no forno TMA possuíam dimensões de $6 \mathrm{~mm}$ de comprimento (DL) x $4 \mathrm{~mm}$ de largura (DL), obtidas após corte numa máquina de corte de precisão com disco diamantado e submetidas a uma decapagem ácida com $50 \%$ de $\mathrm{HNO}_{3}$ e $50 \%$ de $\mathrm{HF}$ durante 30 segundos a fim de remover a camada deformada pelo corte. O equipamento de TMA utilizado é o modelo TMA-60 da Shimadzu, instalado no laboratório de Metalografia da Escola de Engenharia Industrial Metalúrgica de Volta Redonda (EEIMVR) da Universidade Federal Fluminense (UFF). Enquanto que as amostras tratadas nos fornos tipo Mufla possuíam dimensões de $60 \mathrm{~mm}$ de comprimento (DL) x $50 \mathrm{~mm}$ de largura (DT), extraídas de pedaços da chapa do aço na condição BFH através de corte por disco abrasivo de carbeto de silício sob ação de líquido lubrificante/refrigerante. Os fornos do tipo Mufla utilizados são da marca Brasimet, instalados no laboratório de Tratamentos Térmicos da EEIMVR da UFF.

\subsubsection{Preparação Metalográfica e Análise Microestrutural}

De modo a obter as amostras para o ensaio de ultramicrodureza instrumentada, foi conduzida a preparação metalográfica. Na qual após corte com disco abrasivo e embutimento a quente, realizou-se o processo de lixamento com lixas de carbeto de silício $(220,320,400,600,800,1000$ e 1200 mesh), fazendo uso de água como líquido refrigerante e lubrificante. $O$ polimento foi manual e realizado em uma politriz com pano de feltro e pasta de diamante nas granulometrias de 6, 3 e $1 \mu \mathrm{m}$, com lubrificante Azul da Arotec para Ferrosos. Por fim, as amostras foram atacadas com Nital 3\% (3\% de ácido nítrico e $97 \%$ de álcool etílico PA), por esfregamento por 10 segundos, ou até que as amostras ficassem foscas. 


\subsubsection{Ensaio de Ultramicrodureza Instrumentada}

O ensaio de ultramicrodureza instrumentada foi realizado de modo a obter informações quanto as possíveis mudanças nas características mecânicas em pontos distintos das amostras em função das alterações microestruturais. Os ensaios foram executados no Laboratório de Caracterização de Materiais Multiusuários no Instituto de Ciências Exatas (ICEx) da Universidade Federal Fluminense (UFF), em Volta Redonda em um ultramicrodurômetro instrumentado da Shimadzu, Modelo DUH 211S, com indentador do tipo Vickers. Os ensaios foram conduzidos em condição de ciclo de carga e descarga com carga mínima de 0,2 gf e carga máxima de 100 gf, sob velocidade de carregamento/descarregamento de $7,14 \mathrm{gf} / \mathrm{s}$ e $20 \mathrm{~s}$ de permanência na carga máxima. Foram coletadas 10 medidas por amostras em estudo, a $1 / 4$ da espessura, de modo a estimar os valores médio das durezas dinâmicas elasto-plástica (DHV-1) e plástica (DHV-2), módulo da indentação (Eit), dureza da indentação (Hit), e

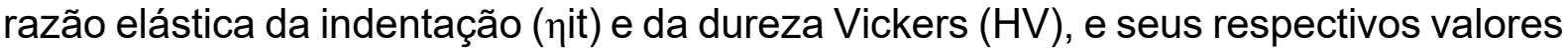
de desvio padrão e erros experimentais. Em todos os casos respeitou-se uma distância mínima de 3 vezes a diagonal da indentação mais próxima [2].

\section{RESULTADOS E DISCUSSÃO}

Para o aço em estudo após o tempo de permanência na temperatura de encharque, ou seja no resfriamento subsequente, enquanto a temperatura permanece no campo bifásico, pode-se formar uma nova ferrita denominada ferrita epitaxial que se forma a partir da austenita tendo como substratos os grãos de ferrita pré-existente e adjacente ao grão de austenita que lhe dá origem (ferrita recristalizada), mesmo sob rápido resfriamento [3]. Formando assim uma microestrutura final composta de ferrita préexistente, ferrita epitaxial e martensita, além da possibilidade de se ter perlita e bainita, em função da temperabilidade da austenita remanescente pós-formação a ferrita epitaxial. Quanto maior a fração dessa ferrita epitaxial formada, maior é o aumento na ductilidade [4], o que seria bastante interessante para o aço em estudo, pois a ductilidade, sendo a capacidade do material ser deformado plasticamente sem que ocorra a ruptura ou a estricção localizada está diretamente ligado ao alongamento. Essas modificações microestruturais foram verificadas através da análise das propriedades mecânicas resultante das medidas obtidas em um ultramicrodurômetro. $\mathrm{Na}$ Figura 1 são apresentados os valores médios da dureza Vickers (HV), com seus respectivos erros experimentais, obtidos na análise via ultramicrodurômetro instrumentado. As amostras oriundas dos tratamentos no Forno e no TMA inicialmente apresentam valores semelhantes de dureza HV. No entanto, ao incrementar a temperatura de encharque os valores da dureza HV entre as amostras do Forno e do TMA tornam-se distintos, onde os valores do TMA estabelecem-se numa faixa inferior aos valores do Forno. Por outro lado, as amostras oriundas do TMA além de apresentarem uma redução nos valores de HV com o incremento da temperatura de encharque, tendo como referência a dureza na condição de $680^{\circ} \mathrm{C}$, verifica-se um desvio no andamento para a condição na temperatura de $760^{\circ} \mathrm{C}$ - a qual apresenta valor de dureza superior ao da condição de $720^{\circ} \mathrm{C}$ - somado ao incremento no erro experimental, tanto no TMA quanto no Forno, para esta condição e as condições no Forno das temperaturas de 880 e $920^{\circ} \mathrm{C}$. 


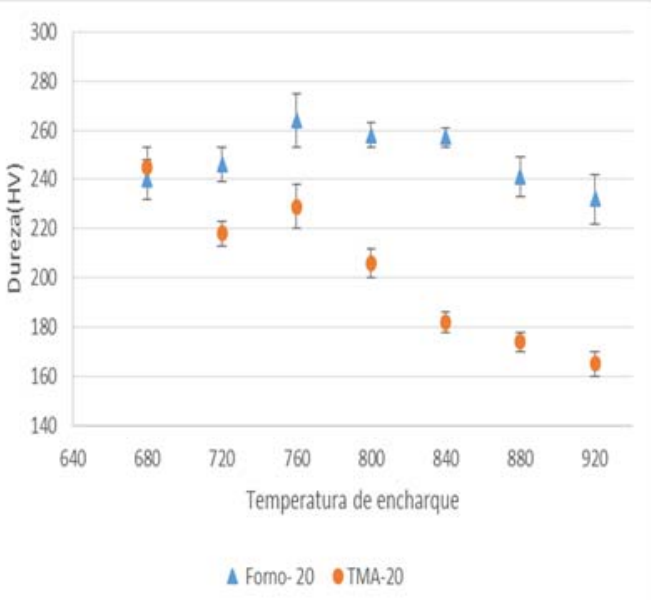

Figura 1. Valores médios calculados para dureza Vickers (HV) para cada temperatura de encharque na condição com patamar isotérmico a $600^{\circ} \mathrm{C}$ por 20 minutos para o Forno e TMA.

A partir de resultados do ensaio de ultramicrodureza pode-se correlacionar os valores obtidos com as propriedades mecânicas, da seguinte forma:

- DHV-1, DHV-2, obtida a partir da força máxima aplicada durante o processo de indentação e a profundidade resultante, onde pode se relacionar a profundidade máxima (dureza dinâmica elasto-plástica - DHV-1) ou a profundidade associada ao perfeito retorno elástico (dureza dinâmica plástica - DHV-2), sendo assim são propriedades que se relacionam com a deformação plástica e elástica.

- A dureza de indentação $\left(\mathrm{H}_{\mathrm{it}}\right)$ é a medida da resistência à deformação permanente, ou seja, momento no qual o esforço associado à penetração da ponta do indentador sobre a superfície do material deixa de ser simplesmente de natureza elástica e tem-se início a deformação plástica. A dureza da indentação (Hit) estaria a associada qualitativamente a tensão limite de escoamento plástico.

- O módulo de indentação $E_{\text {it }}$ que possui valores similares ao módulo de Young ou módulo de elasticidade do material.

- A razão elástica da indentação ( $\left.\eta_{i t}\right)$ que está relacionada com o cálculo entre a parte elástica e total do trabalho (SHIMADZU, Instruction Manual, 2009)

A partir dessas análises fez-se uma comparação entre as amostras do forno e do TMA através de gráficos com os valores médios e seus respectivos erros experimentais referentes a cada propriedade, apresentados na Figura 2. De uma maneira geral, nesse ciclo proposto os valores das propriedades mecânicas, citadas acima, para as amostras obtidas no forno tem-se valores com uma tendência mais significativa do que para as amostras do TMA, tendo em vista que estas últimas apresentam uma dispersão entre os valores das distintas temperaturas.

Comparando de uma maneira geral para os valores médios da dureza Vickers (HV) (Figura 1), durezas dinâmicas DHV-1 e DHV-2 (Figuras 2a,b) e dureza da indentação ( $\left.\mathrm{H}_{\mathrm{it}}\right)$ (Figura 2c) os mesmos seguem a mesma tendência durante todas as temperaturas de encharque. Na temperatura de $680^{\circ} \mathrm{C}$ para DHV-1 e DHV-2 tem-se uma grande discrepância desses valores para as amostras do TMA, resultando em um alto valor para DHV-2 do mesmo, enquanto que no forno são valores próximos. Ocorre novamente um incremento até $760^{\circ} \mathrm{C}$, seguido de uma depreciação para a temperatura de $800^{\circ} \mathrm{C}$, que volta a elevar a $840^{\circ} \mathrm{C}$, seguido de outra redução até a temperatura de $920^{\circ} \mathrm{C}$. 
(a)
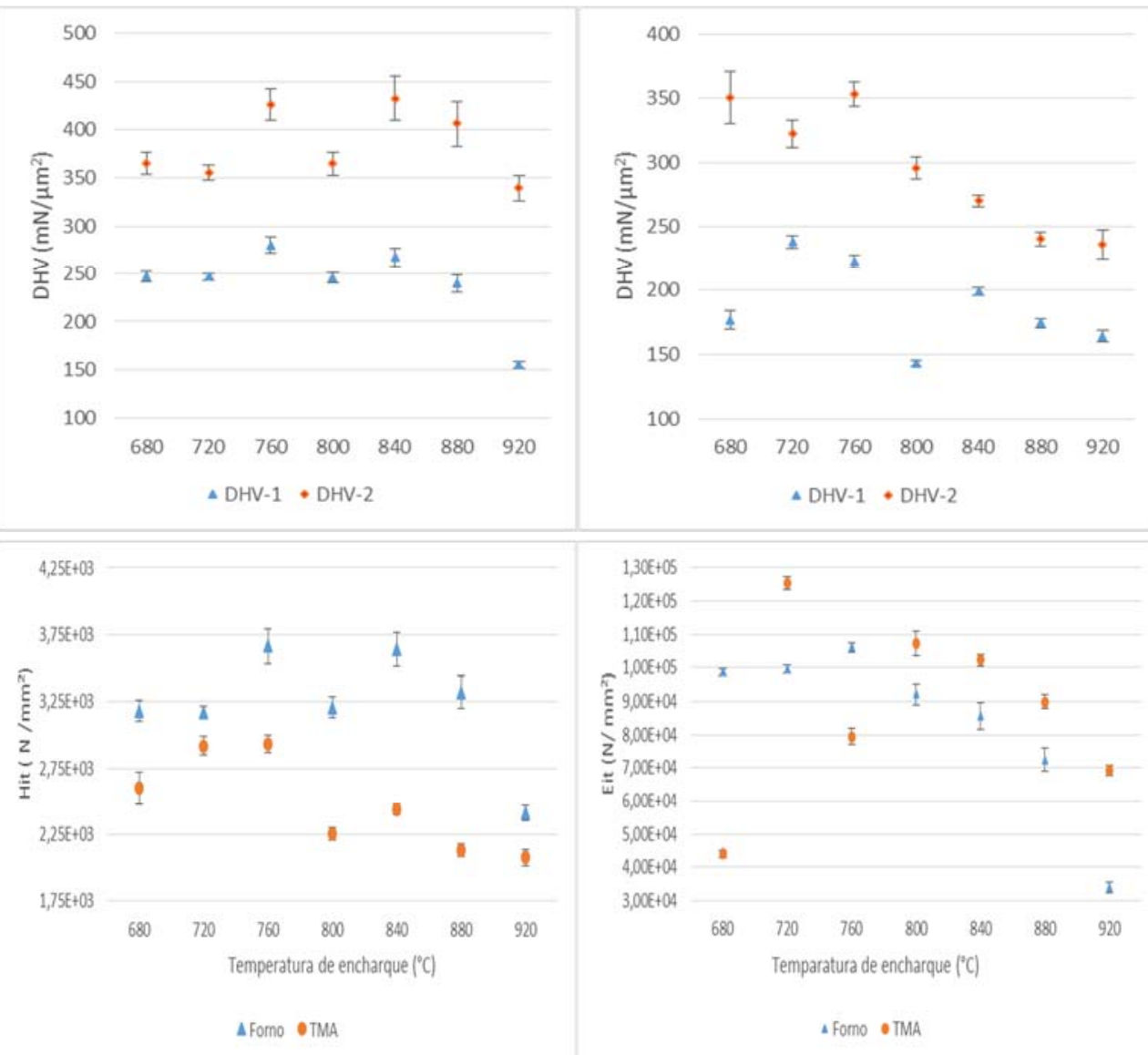

(c)
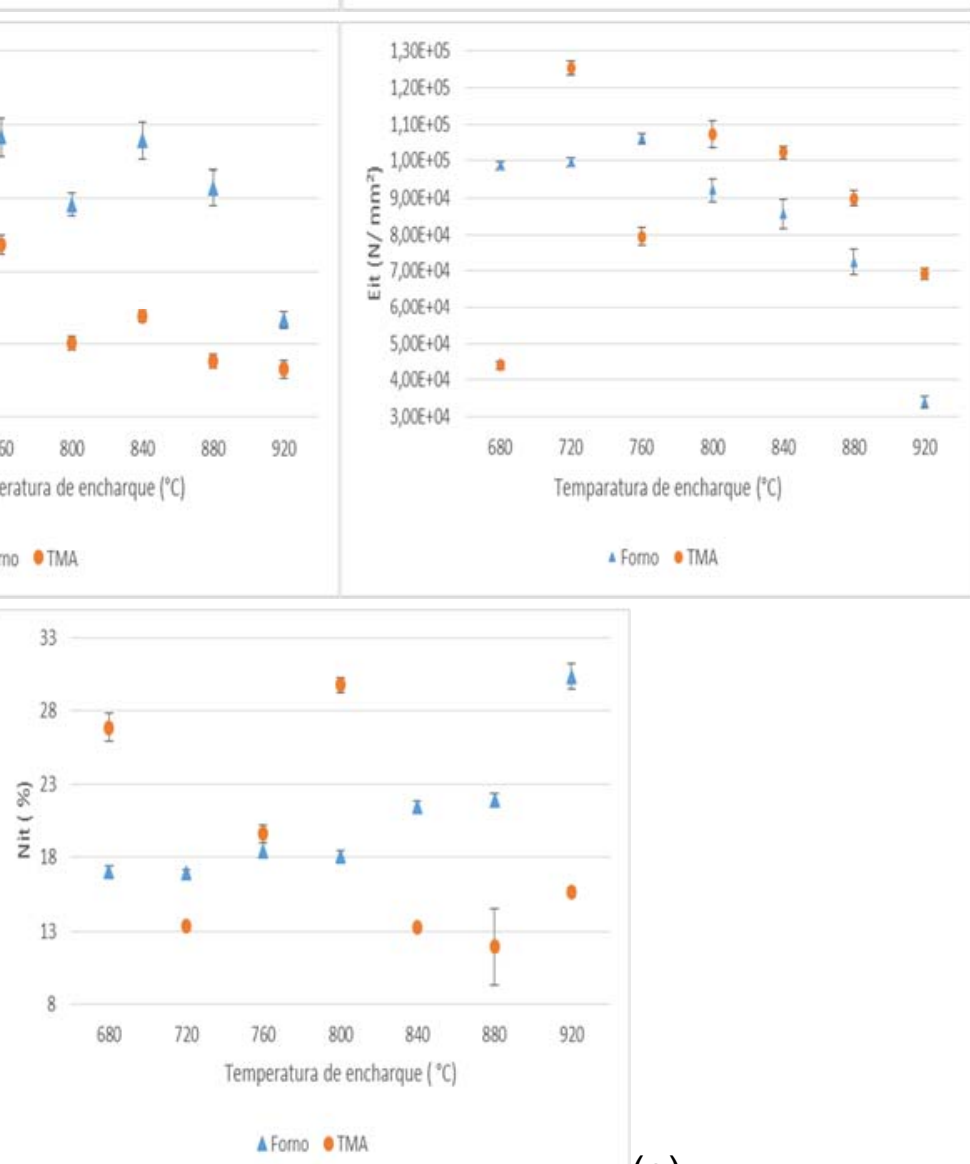

(e)

Figura 2: Propriedades obtidas no ultramicrodurômetro para as amostras com patamar isotérmico a $600^{\circ} \mathrm{C}$ por 20 minutos. (a,b) Comparação DHV-1 e DHV-2, (a) forno e (b) TMA; (c) $H_{i t}$; (d) Eit; e (e) $\eta_{i t}$.

Portanto conforme a Figura $2 \mathrm{~d}$ os valores do módulo de indentação ( $E_{\text {it }}$ ) aumentam com o incremento da temperatura até um máximo na temperatura de encharque de $760^{\circ} \mathrm{C}$, para as amostras do forno, já nas amostras do TMA esse máximo é na temperatura de $720^{\circ} \mathrm{C}$. Nas amostras do forno após esse máximo ocorre uma redução de $E_{\text {it }}$ até a última temperatura de encharque, já no TMA ocorre uma redução brusca para a temperatura de $760^{\circ} \mathrm{C}$ e volta a aumentar para a temperatura de $800^{\circ} \mathrm{C}$ seguido de uma depreciação até a temperatura de $920^{\circ} \mathrm{C}$. Os valores para $\eta_{\text {it }}$ (Figura 2e) principalmente para o TMA, estão bem dispersos, ocorre altos valores para $680^{\circ} \mathrm{C}$ seguido de um decréscimo em $720^{\circ} \mathrm{C}$ que volta a incremente em $760^{\circ} \mathrm{C}$, que tem um aumento brusco para $800^{\circ} \mathrm{C}$ nas amostras do TMA , já para o forno esses valores próximos até $800^{\circ} \mathrm{C}$ que segue com um incremento até a temperatura de $920^{\circ} \mathrm{C}$. 
De maneira geral, com o acréscimo da temperatura, nessa faixa de $680^{\circ} \mathrm{C}$ a $760^{\circ} \mathrm{C}$, pode-se observar nas micrografias apresentadas no trabalho de Gurgel (2016), que ocorre um aumento na quantidade de constituinte MA, em conjunto da redução da fração de matriz ferrítica, contribuindo para o incremento contínuo na resistência ao início da deformação plástica $\left(H_{i t}-\right.$ Figura $\left.2 c\right)$, rigidez elástica $\left(E_{i t}-\right.$ Figura $\left.2 d\right)$ e ductilidade / trabalho plástico, este último associado ao decréscimo de $\eta_{\text {it }}$ (Figura 2e) bem mais significativo nas amostras do TMA, já que no forno os valores foram próximos.

No entanto a significativo incremento na recristalização da ferrita do que incremento na fração de segunda fase nas condições de encharque a $720^{\circ} \mathrm{C}$ no forno, novamente observado nas micrografias de Gurgel (2016), influenciaram significamente para um valor máximo de $E_{i t}$ e consequentemente um valor baixo, mas não mínimo de $\eta_{\text {it. }}$

Quando se compara as propriedades mecânicas extraídas das medidas do ultramicrodurômetro (Figura 2), tem-se uma redução nas durezas HV, DHV-1, DHV-2 para o TMA e $E_{i t}$ (Figuras 1, 2a, b, d) para as temperaturas de 800 e $840^{\circ} \mathrm{C}$, o que se justificaria pela evidencias comprovadas da avançada recristalizada da matriz ferrítica e maior tamanho de grão ferrítico recristalizado, observados novamente no trabalho de Gurgel (2016). Em contrapartida ocorre um aumento de DHV-1, DHV-2 e Hit (Figuras 2c,e) que possivelmente tem relação com a distribuição de fases presente.

Tendo em vista que no trabalho de Ferreira (2013), onde explorou distintas taxas de resfriamento direto associadas a 3 temperaturas de encharque $\left(750,800\right.$ e $\left.850^{\circ} \mathrm{C}\right)$, observou-se nas amostras, matriz ferrítica encruada quando tratadas a $750^{\circ} \mathrm{C}$, recristalização parcial da ferrita a $800^{\circ} \mathrm{C}$ e recristalização total a $850^{\circ} \mathrm{C}$. Além de um incremento da fração de segunda fase com aumento da temperatura de encharque para o meio de resfriamento mais acelerado - em água (Figura 3), e comportamento inverso para os demais meios. Traduzindo num incremento do limite de escoamento (LE), de resistência (LR) e dureza, e decréscimo da ductilidade ( $A L$ ) em função do aumento da severidade do meio de resfriamento para uma mesma temperatura de encharque (Tabela 2). Por outro lado, mantendo-se o mesmo meio de resfriamento, com incremento da temperatura de encharque verifica-se somente para o resfriamento em água um aumento da resistência mecânica e decréscimo da ductilidade, e um comportamento inverso para os meios de resfriamento menos severos (ar e ar forçado).

Quando se compara esse trabalho com o feito por Ferreira (2013), conforme resultados apresentados na Figura 3 e Tabela 2, nota-se a que contribuição do patamar isotérmico em acelerar o avanço da recristalização da matriz ferrítica e formação de segunda-fase associada a MA com o incremento da temperatura de encharque, consequentemente promove mudanças nas propriedades mecânicas da seguinte forma:

- um incremento nas durezas HV, DHV-1, DHV-2 e $\mathrm{H}_{\mathrm{it}}$, pelo incremento tanto na resistência ao início da deformação plástica e a aplicação da carga máxima, pela maior contribuição da segunda-fase associada ao constituinte MA.

- incremento na rigidez elástica $\left(E_{i t}\right)$ e incremento na ductilidade / trabalho plástica (associada a redução no $\eta_{\text {it }}$ ), justificado primeiramente pelo incremento da fração de segunda-fase associada ao MA e em segundo pelo aumento no percentual de recristalização da matriz ferrítica.

Ao compararmos as propriedades mecânicas com os trabalhos de Ferreira (2013), juntamente com as análises de Gurgel (2016) elas contribuem entre si, para as conclusões em relação as propriedades do ensaio do ultramicrodurômetro descrito acima além de evidenciar que as melhores propriedades são obtidas em recozimentos 
intercrítico na faixa de temperatura de encharque entre 760 e $800^{\circ} \mathrm{C}$, sendo interessante uma avaliação para patamares com tempo de permanecia menores, para melhor entendimento de como comportaria essas propriedades mecânicas, visto que esse tempo de 20 minutos no patamar a $600^{\circ} \mathrm{C}$ impactaria na produtividade do material.

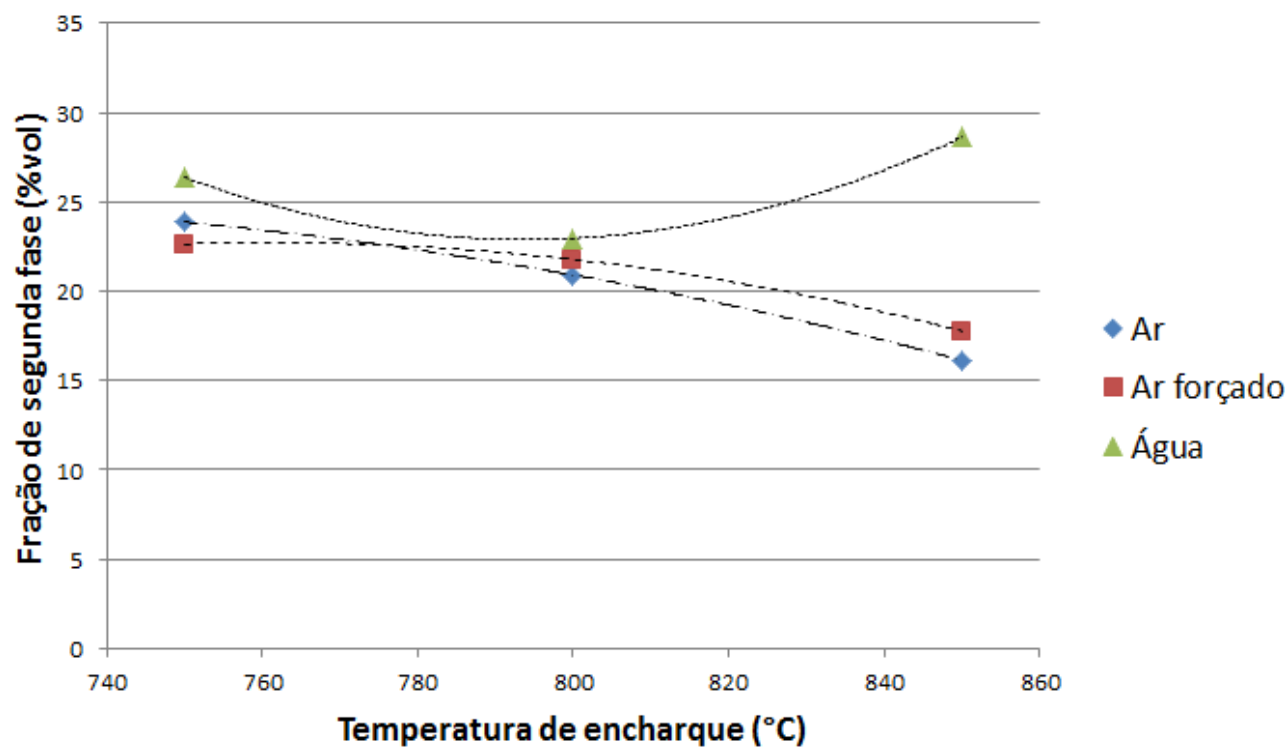

Figura 3. Fração volumétrica de martensita, percentual, para o material em estudo associado as condições de resfriamento direto exploradas por Ferreira (2013).

Tabela 2. Propriedades mecânicas do material em estudo associado as condições de resfriamento direto exploradas por Ferreira (2013).

\begin{tabular}{|c|c|c|c|c|c|}
\hline \multicolumn{2}{|c|}{ Identificação } & \multirow{2}{*}{$\begin{array}{c}\mathrm{LE} \\
(\mathrm{MPa})\end{array}$} & \multirow{2}{*}{$\begin{array}{c}\mathrm{LR} \\
\text { (MPa) }\end{array}$} & \multirow{2}{*}{$\mathrm{Al}(\%)$} & \multirow{2}{*}{$\begin{array}{c}\begin{array}{c}\text { Dureza } \\
\text { (HB3000) }\end{array} \\
\end{array}$} \\
\hline Encharque $\left({ }^{\circ} \mathrm{C}\right)$ & Meio de resfriamento & & & & \\
\hline \multirow{3}{*}{750} & $\mathrm{Ar}$ & 408 & 723 & 11,3 & 200 \\
\hline & Ar forçado & 433 & 745 & 12,2 & 195 \\
\hline & Água & 475 & 795 & 9,1 & 222 \\
\hline \multirow{3}{*}{800} & $\mathrm{Ar}$ & 379 & 671 & 15,3 & 176 \\
\hline & Ar forçado & 396 & 701 & 12,6 & 185 \\
\hline & Água & 529 & 856 & 5,9 & 231 \\
\hline \multirow{3}{*}{850} & $\mathrm{Ar}$ & 323 & 579 & 24,5 & 159 \\
\hline & Ar forçado & 332 & 601 & 19,7 & 162 \\
\hline & Água & 921 & 1110 & 2,7 & 279 \\
\hline
\end{tabular}

\section{CONCLUSÃO}

Com base nos resultados obtidos e discussão apresentado, o presente estudo da caracterização microestrutural de um aço baixo carbono com micro adição de molibdênio e nióbio, pode-se concluir que:

- Uma temperatura crítica para o encharque favorável para a obtenção de melhores propriedades mecânicas seria na faixa de 760 a $800^{\circ} \mathrm{C}$.

- O estudo do comportamento do material através das propriedades extraídas pelo ensaio de ultramicrodureza instrumentada, associado a características do comportamento mecânico vinculadas a parcela elástica de deformação (DHV-1 e $E_{i t}$ ), permitiu separar os resultados associadas a uma maior contribuição de fases duras 
em conjunto com uma matriz ferrítica pela faixa de valores atribuídos a estas propriedades.

- A utilização do ultramicrodurômetro instrumentado mostrou ser uma ferramenta com potencial para avaliação das propriedades mecânicas neste tipo de material e predição de propriedades de tração.

\section{Agradecimentos}

Os autores agradecem a CSN por ter fornecido o material estudado. A UFF pelos recursos para preparação e caracterização microestrutural. Ao IME pela utilização do MEV. Ao Laboratório de Caracterização de Materiais Multiusuários no Instituto de Ciências Exatas (ICEx) da UFF. M.A.M. Gurgel agradece a bolsa de mestrado subsidiada pela CAPES vinculada ao PPGEM/UFF e a bolsa de doutorado subsidiada pela CAPES ao PGCM/SE4-IME.

\section{REFERÊNCIAS}

1 ULSAB-AVC. Technical Transfer Dispatch \#6. AISI, Southfield, MI, 2001 ULSAB-AVC, 2001.

2 SHIMADZU Dynamic Ultra-micro Hardness Tester, DUH-211/ DUH-211S Instruction Manual, May 2009. (SHIMADZU Instruction Manual, 2009).

3 DIEHL NETO, B. Comparação da influência dos parâmetros industriais na microestrutura de dois aços dual-phase. Porto Alegre, 2009. Trabalho de Conclusão de Curso - Escola de Engenharia de Materiais - Universidade Federal do Rio Grande do Sul (UFRGS), Porto Alegre, 2009.

4 ANDREWS, F. W. K. Empirical Formula for the Calculation of Some Transformation Temperatures, J. Iron and Steel Inst.: 203, p. 721-27, 1965.

5 Gurgel M.A.M. Evolução estrutural de um aço DP laminado a frio e submetido ao recozimento intercrítico sob distintas condições de resfriamento. In: Associação Brasileira de Metalurgia, Materiais e Mineração. Anais do $53^{\circ}$ Seminário de Laminação - Processos e Produtos Laminados e Revestidos, parte integrante da ABM Week, a ser publicado em 2016, Rio de Janeiro, RJ, Brasil, ABM, 2016.

6 Ferreira F.G.N., Influência dos Parâmetros de Recozimento Intercrítico para Obtenção de Aços Bifásicos. In: Associação Brasileira de Metalurgia, Materiais e Mineração. Anais do $50^{\circ}$ Seminário de Laminação - Processos e Produtos Laminados e Revestidos, 2013, Ouro Preto, MG, Brasil, ABM, 2013. 